\title{
Perspectivas Didáticas Atuais para a Matemática no Ensino Médio
}

Perspectivas educativas actuales de las matemáticas em la escuela secundaria

\author{
S. D. Nascimento*; D. N. Souza; A. C. Santos; \\ Programa de Pós-Graduação em Ensino de Ciências e Matemática, NPGECIMA, Universidade Federal de Sergipe, \\ 49.100-00, São Cristóvão-Sergipe, Brasil \\ *shirleyd_nd@hotmail.com \\ (Recebido em 24 de fevereiro de 2016; aceito em 29 de outubro de 2016)
}

\begin{abstract}
Esse trabalho teve como objetivo fomentar uma discussão no tocante das perspectivas didáticas atuais para o ensino da matemática no ensino médio a partir das recomendações presentes nos documentos oficiais que fundamentam esse ensino. Buscou-se discutir sobre o tratamento didático, que apontam propostas de currículos a serem desenvolvidas pelas escolas devem incluir competências básicas, conteúdos e formas de tratamento dos conteúdos coerentes com os princípios pedagógicos de identidade, diversidade e autonomia, e também os princípios de interdisciplinaridade e contextualização, adotados como estruturadores do currículo do Ensino Médio. E a posterior por uma análise dos resultados obtidos através de uma investigação para sabermos como a contextualização e a interdisciplinaridade têm sido interpretadas no exercício da prática do docente de matemática; como mobilizam o interesse dos discentes pela matemática como os discentes percebem a importância da matemática e como esperam que seja ensinada. Para tanto, nos reportamos as contribuições teóricas introduzido por Passos (2006), Charlot (2000, 2005 ) e ainda, por Santomé (1998), Tufano (2001), Ole Skovsmose (2001) D’Ambrosio (1989).
\end{abstract}

Palavras chaves: Ensino Médio; Contextualização; Interdisciplinaridade.

Este estudio tuvo como objetivo fomentar una discusión con respecto a las perspectivas actuales de la educación para la enseñanza de las matemáticas en la educación secundaria a partir de las presentes recomendaciones en los documentos oficiales que apoyan esta enseñanza. Hemos tratado de discutir el tratamiento didáctico, señalando plan de estudios propuesto para ser desarrollado por las escuelas deben incluir habilidades básicas, contenidos y formas de tratar los contenidos coherentes con los principios pedagógicos de la identidad, la diversidad y la autonomía, así como los principios de interdisciplinariedad y contextualización, adoptado como una estructuración curricular de la escuela secundaria. Y más tarde por un análisis de los resultados obtenidos a través de una investigación para saber cómo contextualización y la interdisciplinariedad se han interpretado en el ejercicio de la práctica de enseñanza de las matemáticas; para movilizar el interés de los estudiantes en matemáticas que los estudiantes se dan cuenta de la importancia de las matemáticas y cómo esperan que se les enseñe. Para esto, nos referimos a las contribuciones teóricas introducidas por Pasos (2006), Charlot (2000, 2005) y también por Santomé (1998), Tufano (2001), Ole Skovsmose (2001) D'Ambrosio (1989).

Palabras clave: La escuela secundaria; contextualización; lainterdisciplinariedade

\section{INTRODUÇÃO}

Para desenvolvermos os pontos centrais que estão sinalizados nesse trabalho, sublinhamos inicialmente a questão do saber matemático, a questão do sentido, considerando o que nos diz Charlot (2005)[1] quando afirma que o desejo deve servir como fonte para que haja uma mobilização para aprender. Para Charlot (2005)[1], a mobilização nasce no sujeito a partir do sentido encontrado ao apropriar-se de um determinado saber e do prazer a ser despertado por esse conhecimento. Esse autor utiliza a palavra mobilização em vez de motivação, pois compreende que mobilização é um desejo pessoal que transcende para a realização de atividades, seja ela de qualquer cunho, enquanto a motivação é propiciada ao indivíduo por um ambiente ou por terceiros. Assim, ele apresenta também que quando o saber matemático é mobilizado, ele é desejado pelo aluno 
quando investido de sentido do que aprende e do prazer proporcionado com esse aprendizado. Dessa forma, a didática deve incorporar a equação aprender representada pela atividade que conduz ao aprendizado, o sentido do aprender e o prazer em aprender. Nisso tudo, deve-se ter a articulação destacada por Passos (2006, p.14)[2], que afirma que o ensino é mais que uma tarefa, "é um modo de trabalho que reúne elementos articulados, isto é, o professor, o estudante e o conhecimento".

Partindo dessas referências, que fundamentam nosso trabalho, direcionamos uma reflexão a partir das mais novas configurações apresentadas nos documentos oficiais para o ensino médio: Lei de Diretrizes e Bases da Educação Nacional - LBB (2006)[3] e as Diretrizes Curriculares para o Ensino Médio - DCNEM (2012)[4].

A ideia que baliza o ensino médio como etapa conclusiva da educação básica para todos é a de não reduzir esse nível de ensino a uma fase preparatória para o ensino superior ou estritamente profissionalizante. A máxima pretendida na legislação é que o ensino médio deve formar cidadãos éticos e autônomos, capazes de compreender os processos produtivos, de forma que, ao concluírem esse ciclo de ensino, estejam preparados para a vida adulta em sociedade.

E de acordo com as DCNEM, o currículo é organizado em áreas de conhecimento, a saber, que integram:

I-Linguagens; II - Matemática; III - Ciências da Natureza; IV-Ciências Humanas. $\S 1^{\circ} \mathrm{O}$ currículo deve contemplar as quatro áreas do conhecimento, com tratamento metodológico que evidencie a contextualização e a interdisciplinaridade ou outras formas de interação e articulação entre diferentes campos de saberes específicos (BRASIL, 2012, p. 3).

De acordo com esse documento, as áreas de conhecimento se organizam e interligam disciplinas, mas não as diluem nem as eliminam. A organização por áreas de conhecimento não exclui componentes curriculares com especificidades e saberes próprios construídos e sistematizados, mas implica no fortalecimento das relações entre eles e a sua contextualização para apreensão e intervenção na realidade. As propostas de currículos a serem desenvolvidas pelas escolas devem incluir competências básicas, conteúdos e formas de tratamento dos conteúdos coerentes com os princípios pedagógicos de identidade, diversidade e autonomia, e também os princípios de interdisciplinaridade e contextualização, adotados como estruturadores do currículo do Ensino Médio.

O artigo de Wartha, Silva e Bejarano (2013)[5] reúne contribuições de outros artigos quanto as vastas concepções do termo contextualização relacionado a recurso didático, alertando-nos sobre a utilização dos termos contextualização e cotidiano, que muitas vezes são usados como sinônimos.

Ou seja, é verdade que existe uma convocação reforçada nos documentos oficias para a necessidade de ensinar de forma contextualizada. Porém, é importante considerar que contextualizar não é encontrar aplicações práticas, a qualquer preço, para os conteúdos a serem ensinados, inclusive em Matemática. É preciso considerar também particularidades e especificidades no âmbito de cada disciplina.

A interdisciplinaridade e a contextualização trazem consigo um grande desafio de transformarem-se em práticas escolares efetivas. Além de buscarem a superação da hierarquização ou agrupamento dos conteúdos para adequar à realidade dos alunos, convocam professores a rever e a refletir sobre a prática pedagógica e as concepções assumidas por eles frente à questão da contextualização.

Consideramos as ponderações feitas por Potiguara (2008) [6] ao sugerir que para a superação de dicotomias e das visões fragmentadas é importante não sacramentar conceitos a exemplo da interdisciplinaridade na sua perspectiva ingênua e superficial de integração de conteúdos ou da negação da identidade de cada umas das disciplinas cientificas.

Para não se enraizar nessas perspectivas, entendemos que a comunicação configura-se em um importante recurso pedagógico para práticas que contemplem a interdisciplinaridade e a contextualização, conforme já enfatizava Fazenda (2011, p.11)[7] sobre a importância da metodologia não como um fim. "A importância metodológica é indiscutível, porém é necessário não fazer dela um fim, pois interdisciplinaridade não se ensina nem se aprende, apenas vive-se, exerce-se e, por isso, exige uma nova pedagogia, a da comunicação".

Diante disso, o nosso objeto de estudo consistiu de uma pesquisa com docentes de matemática do Ensino Médio e com discentes desses, tendo como objetivo investigar como a 
interdisciplinaridade tem sido interpretada ou abordada pelos docentes de matemática; como esses docentes mobilizam o interesse dos discentes pela matemática; como os discentes percebem a importância da matemática e como esperam que seja os conteúdos ensinados.

\section{MATERIAL E MÉTODOS}

A pesquisa foi realizada em 2015, com 5 professores de matemática do ensino médio e 17 alunos desses professores. Entre os estudantes participantes da nossa investigação, 3 eram de uma escola da rede pública Estadual do interior da Paraíba e 14 do ensino médio integrado do Instituto Federal de Sergipe (IFS). Dos 5 professores entrevistados, 1 estava lecionando em uma escola pública estadual do interior da Paraíba; 2 atuam no Instituto Federal de Educação Ciência e Tecnológia de Sergipe/IFS, 1 não estava lecionando à época da pesquisa e 1 estava lecionando em uma escola municipal de Aracaju. Esses participaram espontaneamente após terem sido convidados.

Os participantes do IFS foram escolhidos por atuarem na modalidade de ensino integrado, que abrange a formação em ensino médio e ensino técnico ao mesmo tempo, onde se entende que a interdisciplinaridade deve consistir em um dos princípios articuladores do currículo dos cursos técnicos de nível médio. Após iniciar a pesquisa, uma visita a uma escola do interior paraibano fez despertar o interesse de se conhecer as ideias de professores e estudantes da escola, que oferta o ensino médio pela Secretaria de Estado da Educação da Paraíba. Embora, não tenha sido objetivo comparar os contextos distintos, mas, sobretudo analisar como a interdisciplinaridade e a contextualização estão se efetivando adotadas ou abordadas nessas escolas.

$\mathrm{O}$ estudo constou de entrevistas, sendo de natureza qualitativa, com foco nos docentes e discentes. As respostas dos participantes foram transcritas com a finalidade de melhor avaliar seus aspectos. Os indivíduos responsáveis pelas falas estão classificados da seguinte forma: PMPB (professor de matemática da Paraíba); PMSE (professor de matemática de Sergipe); AMPB (aluno do ensino médio da Paraíba); e AMSE (aluno do ensino médio Sergipe).

\section{RESULTADOS E DISCUSSÃO}

A seguir, são apresentadas as perguntas que nortearam a pesquisa, juntamente com as respectivas análises das respostas dadas pelos participantes, e as nossas considerações.

\subsection{Considerações sobre o que nos dizem os docentes e discentes}

Ao perguntarmos aos professores como mobilizam os seus alunos a se interessarem pela matemática, os professores responderam:

\footnotetext{
"Trabalhando com metodologias diferenciadas, principalmente com jogos, resolução de problemas como metodologia e TIC's. Busco abordar os conteúdos com metodologias que tirem a monotonia de uma aula expositiva, na qual o professor copia no quadro o que considera importante e os alunos, por sua vez, transcrevem para os seus cadernos" (PEMSE).

"Depende do perfil da turma, em alguns casos a maioria dos alunos já sabe que um bom entendimento de matemática é fundamental para sua formação intelectual. Mas na maioria dos casos a realidade não é essa; nesses casos procuro primeiro tentar mostrar que a matemática não é um "bicho papão" $e$ que pode ser útil no cotidiano; em seguida, tento apresentar os conteúdos conforme sua construção histórica (nem sempre isso é possível!) e com isso os alunos podem perceber o que motivou a descoberta e o desenvolvimento do assunto em questão. Outro recurso que costumo utilizar é a realização de oficinas de resolução de problemas, onde procuro fazer com que os alunos sintam a necessidade de conhecer determinado assunto para resolver os problemas propostos, e daí os alunos se sentem motivados a aprender para resolver o problema" (PEMSE).
} 
Incentivando-os a observar o mundo a sua volta, de forma que eles percebam que a matemática está presente em tudo. E seu entendimento facilita a nossa vida cotidiana" (PEMSE).

"Inicialmente, mostrando as aplicações práticas da Matemática na vida cotidiana deles; em seguida, acredito que é preciso trabalhar com atividades diferenciadas que possibilitem aos alunos compreender melhor o conteúdo matemático que está sendo abordado, uma vez que uma possível causa para a falta de interesse pode ser justamente o fato de não conseguirem entender o conteúdo estudado"(PEMSE).

“A matemática possui um campo de atuação muito abrangente. O tempo de aula é restrito a ponto de não dar tanto espaço para abordar além dos conteúdos. Todavia, em horários opostos pode-se realizar trabalhos que visem um maior empenho, interesse e motivação para se estudar $e$ aprender realmente a matemática. Na escola em que trabalho, por exemplo, temos grupos de estudos referentes a olímpiadas de matemática, cursos de robótica, montagem de cubo mágico e laboratório de matemática e informática" (PEMPB)"

E ao serem questionados sobre como mostram o sentido da matemática para a vida cotidiana do aluno, obtivemos as seguintes respostas:

\begin{abstract}
"Depende muito do conteúdo que é trabalhado. De forma geral, tento fazer com que os alunos se apropriem de determinado problema e se sintam responsáveis por resolvê-lo, feito isso, é só mostrar como o conteúdo trabalhado em sala de aula pode ser útil para ajudá-los na resolução. Vale destacar que nem todos os conteúdos de matemática do ensino básico possuem aplicações efetivas no diaa-dia, muitos compõem a matriz curricular com o objetivo de desenvolver o raciocínio lógico, nesses o desafio é maior, e para dar algum sentido ao seu estudo procuro sempre trazer uma curiosidade sobre o tema" (PEMSE).

"Mostrando que em todas as coisas do dia a dia existe matemática, e também buscando relacionar o conteúdo trabalhado em sala de aula com objetos que são comuns aos alunos" (PEMSE).

"Acredito que o uso das operações básicas está investido no cotidiano de todos. Operar corretamente, seja com dinheiro ou com objetos geométricos, dá certo sentido, pois rotineiramente nos deparamos com tais operações. Para ensinar mostrando sentido devemos inicialmente considerar o universo no qual o aluno está inserido e a partir dele buscar alternativas para mostrar onde aplicar no cotidiano os temas abordados na sala de aula" (PEMPB).
\end{abstract}

Em suas respostas, os docentes dizem que mobilizam os seus alunos a se interessarem pela matemática apresentando o sentido e a relação dela com a vida cotidiana. Lembremos que para Charlot (2000)[8] o saber matemático é mobilizado, ou seja, é desejável pelo aluno quando investido de sentido do que se aprende e do prazer a ser gerado com esse aprendizado. Encontramos assim a compreensão de que:

- É preciso lançar mão de estratégias didáticas para mobilizar o interesse dos alunos pela matemática, e isso os professores demonstram fazer, como pode ser observado na fala de um deles: "Busco abordar os conteúdos com metodologias que tirem a monotonia de uma aula expositiva...". Muito provavelmente, o que esse professor almeja é que a matemática seja vista como situações que envolvam a resolução de problemas, para os alunos se sintam motivados para propor solução, apontando direções, formulando questões e tomando decisões (NACARATO, 2013)[9]. Isso pode ser observado também quando um dos professores diz que "De forma geral, tento fazer com que os alunos se apropriem de determinado problema e se sintam responsáveis por resolvê-lo...". Em sua fala, esse professor demonstra também que não quer ser o transmissor do conhecimento, mas um agente mobilizador. Considerando-se a ideia de Beatriz D'Ambrósio (1989)[10], de que para ocorrer uma renovação no ensino da matemática, primeiramente precisa-se modificar as concepções dos alunos e professores, tem-se que os professores aqui entrevistados já se mostram com concepções modificadas ou dispostos a renovar o ensino da matemática.

A abordagem de um conteúdo matemático considerando a sua construção histórica pode ser uma estratégia para superar a ideia da matemática como matéria "bicho papão", foi também sugerida 
por um dos nossos entrevistados. Conforme afirmam Lopes, Victer e Souza (2014)[11], a História da Matemática pode servir como um instrumento eficaz para o ensino e a aprendizagem de matemática, pois possibilita que os alunos compreendam conceitos a partir de suas origens, considerando a evolução deles ao longo do tempo. Essa metodologia, abordagem histórica da matemática, também, é considerada por Celi Spasandin Lopes (2011)[12] como um importante elemento de contextualização dos objetos do conhecimento que formam a relação didática.

- Definir a ação didática, quando possível, a partir de um estudo do perfil da turma. Também aqui encontramos indícios de que os professores têm essa preocupação. Na fala "Para ensinar mostrando sentido devemos inicialmente considerar o universo no qual o aluno está inserido e a partir dele buscar alternativas", observamos que o professor afirma ter a preocupação de conhecer melhor o aluno (ou a turma) antes de escolher a forma de abordagem do conteúdo. Essa compreensão sobre as "condições socioculturais, expectativas e competência cognitiva dos alunos" já é aconselhada nos Parâmetros Curriculares Nacionais (PCN) para Matemática (1999, p. 40)[13].

\title{
Os docentes dizem como a matemática é contextualizada:
}

\begin{abstract}
"Por meio de situações problemas e atividades que tratem da realidade do aluno, como citado na questão anterior (as feiras e mercadinhos)" (PEMSE).

"Através de oficinas de resolução de problemas, estudo de caso (utilizando uma situação do dia-a-dia onde a matemática está presente)” (PEMSE).

"Através de situações-problemas, envolvendo o assunto dentro da vida do aluno. Mostrando o quanto é importante à leitura, interpretação. Evitando o máximo cálculo mecânico" (PEMSE).
\end{abstract}

Encontramos o registro de dificuldade para conciliar atividades contextualizadas que requerem planejamento, tempo e dedicação com grandes números de turmas/leciona. Embora, explicitaram sobre a importância e entendimento, devemos considerar o contexto onde o aluno está inserido, além de ser ressaltado a compreensão que não são todos os conteúdos que tem necessária relação com aplicações efetivas com o cotidiano, ou seja, os conteúdos podem ser contextualizados e não ter uma aplicação efetiva em algum momento específico do conteúdo. Essa observação ponderada considera a particularidade e especificidade própria da disciplina, a exemplo da matemática. Para Tufano (2001)[14] "a contextualização é um ato particular e delicado. Cada autor, escritor, pesquisador ou professor contextualiza de acordo com suas origens, com suas raízes, com o seu modo de ver e enxergar as coisas com muita prudência, sem exagerar." De fato, concordamos que contextualizar não é encontrar aplicações práticas a qualquer preço.

Os docentes dizem ainda, que efetivam atividades contextualizadas na disciplina de matemática através do uso da resolução de problemas; não ressaltado outros exemplos, como a modelagem, a etnomatemática. A resolução de problema para Celi Espasandin Lopes (2011)[12] é uma das formas de organização das atividades de ensino de Matemática que considerem a contextualização, não sendo a única, portanto.

Em quais momentos os conteúdos ensinados em matemática dialogam com as demais disciplinas?

\footnotetext{
"Quando eu cito exemplos do uso da matemática em situações do cotidiano, por exemplo, em Geografia se estuda localização geográfica, que utiliza matemática, explico como funciona, mas não existe um diálogo direto entre as disciplinas (professores). Não há projetos na escola que ofereçam a interdisciplinaridade" ( PEMSE).

"Geralmente há um diálogo com outras disciplinas justamente na hora da contextualização, por exemplo, quando estudamos RAZÃO (conteúdo normalmente visto no $7^{\circ}$ ano do ensino fundamental) uma aplicação direta e ESCALA que é um conteúdo de Geografia e desenho geométrico, quando estudamos FUNÇÃO AFIM (conteúdo geralmente visto no $1^{\circ}$ ano do ensino Médio) uma apliacação direta é MRU(Movimento Retilineo Uniforme) que é um conteúdo de Física, existem inúmeros outros exemplos"(PEMSE).
} 
"Com a disciplina Português em quase todos os momentos, devido à necessidade da interpretação. Com as demais disciplinas sempre que possível, a depender do assunto e sua relação com a disciplina. Em suma toda situaçãoproblema permite fazer a conexão da matemática com outra disciplina" (PEMSE).

O docentes têm a compreensão de que interdisciplinaridade consiste em utilizar os conhecimentos de outras ciências para resolver um problema ou compreender um determinado fenômeno, sob diferentes pontos de vista, mas que na prática de suas realidades a interdisciplinaridade não se efetiva, como o proposto por Santomé (1998)[15], quando considera que as diferentes áreas do conhecimento devem "entrelaçar-se, complementar-se e reforçar-se mutuamente", consistindo-se como marco da integração dos saberes.

Afirmam que não existem projetos interdisciplinares, há uma tentativa particular de mostrar relação da sua disciplina com os demais, exemplificando aproximação com a geografia, que há um diálogo na hora da contextualização e foi ressaltada a importância da disciplina de português para ajudar na interpretação dos problemas matemáticos. Foi ressaltado, que toda situação-problema permite fazer a conexão da matemática com outra disciplina.

\section{Qual a importância da matemática?}

"Ela é a base de todos os outros estudos, de todos os "problemas" e a base da evolução tanto tecnológica como humana” (AMPB).

"É importante para fazer cada tipo de cálculo quando for preciso. Saber fazer as contas das despesas, quanto posso gastar, economizar entre outros" (AMSE).

“Tudo, pois a matemática está presente em tudo aquilo que fazemos, até nas coisas mais simples que quase nem percebemos sua presença” (AMSE).

"Em primeiro lugar a matemática evoluiu o mundo das tecnologias avançadas, criação de maquina entre outras coisas, não seria possível ter criado isto tudo sem a interferência da matemática. Ela tem para todos, uma importância simbólica e real" (AMPB).

\section{Como a matemática deveria ser ensinada?}

"De forma mais simples e diferente, não só com os alunos e os cadernos, mas usando outras formas de mostrar a matemática, sem ser menos eficiente" $(A M P B)$.

"De forma interativa, de um jeito que todos entendam, de forma simples mesmo, sendo de forma lenta, mas que todos no final de uma aula tenham um grande desenvolvimento" (AMSE).

"Como ela é vista como um bicho de sete cabeças deve ser trabalhada de forma interativa desde o primeiro contato na escola "(AMSE).

Identificamos que a matemática é importante para os discentes porque tem relação com a vida, por explicar e ajudar a resolver problemas práticos do dia a dia, além de ser base para outras áreas e para as conquistas tecnológicas. Porém, em geral, opinam que a matemática deveria ser ensinada de maneira mais fácil e de forma simples, clara, interativa e lúdica. Consideram que o ensino da matemática, não é atrativo, não é estimulante, não é motivador.

Nesse momento, indagamos como esse saber, pode ser desejado? Ele simplesmente parece não ser, não é ou ainda não é, pois ao reconhecerem a importância da matemática não corresponde que esse saber esteja sendo ensinados sincronizados com o seu sentido, com o sentido que os discentes relacionaram. Ou seja, na realidade, a matemática parece continuar a ser ensinada na escola pelos seus agentes como um corpo de conhecimento polido e acabado, como sinaliza D' Ambrosio (1989) [10]. Não é, portanto, dada a oportunidade ao aluno de criar, de se relacionar e de se interessar por esse saber.

D’ Ambrosio (1989, p, 15) [10] nos diz que: 
O aluno, acreditando e supervalorizando o poder da matemática formal perde qualquer autoconfiança em sua intuição matemática, perdendo, dia a dia, seu "bom-senso" matemático. Além de acreditarem que a solução de um problema encontrada matematicamente não estará, necessariamente, relacionada com a solução do mesmo problema numa situação real.

Para Skovsmose (2001)[16] a escola deve capacitar os alunos para analisar as informações de cunho matemático na realidade com os quais se depara aproveitar as questões significativas presentes na sociedade e que os problemas matemáticos devem ter significados para o aluno. $\mathrm{O}$ autor considera que a matemática interfere na realidade e propõe o ensino de uma matemática crítica que adota uma postura reflexiva diante das informações matemáticas

Lembrando que os docentes dizem que mobilizam os seus alunos a se interessarem pela matemática apresentando o "seu sentido" e sua relação com a vida cotidiana. Exemplos não identificados nos depoimentos dos alunos. Devido isso, novas reflexões e inquietações nos motivam a continuar nossa pesquisa.

\section{CONCLUSÃO}

O presente trabalho objetivou analisar a concepção dos docentes sobre as perspectivas didáticas para a matemática no ensino médio referentes à contextualização e a interdisciplinaridade e como se efetiva na práxis, como também, relacionar a percepção dos alunos no âmbito dessa questão. Tendo em suas questões norteadoras, saber como os docentes mobilizam os alunos a se interessarem pela matemática e como a ensinam; Qual é a compreensão dos docentes sobre a interdisciplinaridade e contextualização que aparecem como possibilidade didática, nas DCNEM (2012)[4]; Como a contextualização e a interdisciplinaridade se efetivam na disciplina de matemática? Como os alunos percebem a relevância da matemática para a sua vida prática (cotidiana) e como esperam/desejam que seja ensinada na escola?

A interdisciplinaridade e contextualização aparecem como possibilidade didática, nas DCNEM (2012)[4] propondo a superação do tratamento isolado e fragmentado do ensino, superar o arbítrio da proposição de áreas, ou agrupamentos de conteúdos, adequando-as às características dos alunos e do ambiente socioeconômico. De acordo com o documento, a interdisciplinaridade e a contextualização, ou outras formas de interação e articulação entre diferentes campos de saberes específicos podem possibilitar a reorganização das experiências dos agentes da escola, de forma que revejam suas práticas, discutam sobre o que ensinam e como ensinam.

Percorremos um itinerário onde as perspectivas didáticas atuais para o ensino apontam para uma convocação de reorganização na forma de conceber o ensino, para sair do paradigma meramente disciplinar. E a contextualização do conhecimento matemático em conteúdos de outras disciplinas é uma das formas de mostrar a contribuição desse conhecimento na leitura dos diversos fenômenos naturais e sociais em que outras ciências se apresentam.

Com base em nossas considerações, apontadas no formato desse texto, sobre o que dizem os docentes e discentes no âmbito das questões presentes nesse trabalho, das quais, consideramos embrionário, finalizamos no momento essa etapa, entendendo sobre a necessidade de ampliarmos um estudo ainda mais atento para as nossas questões aqui colocadas, além de outras inquietações que surgiram nesse início de trabalho que nos motivam a contemplar novas escutas para ampliarmos a discussão no tocante a questão didática para matemática no ensino médio na perspectiva se uma prática contextualizada e interdisciplinar. 


\section{REFERÊNCIAS BIBLIOGRÁFICAS}

1. CHARLOT, B. Relação com o Saber, Formação de Professores e Globalização: Questões para a educação hoje. Porto Alegre: Ed. Artmed, 2005.

2. VEIGA, IPA(Org). Lições de Didática. Campinas/SP: Papirus, 2007.

3. BRASIL. Senado Federal. Lei de Diretrizes e Bases da Educação Nacional: no 9394/96. Brasília: 1996.4.

4. BRASIL. Conselho Nacional de Educação. Câmara de Educação Básica. Diretrizes Curriculares Nacionais para a Educação Profissional Técnica de Nível Médio. O Presidente da Câmara de Educação Básica do Conselho Nacional de Educação. Ministério da Educação, 2012.

5. WARTHA EJ, SILVA EL, BEJARANO NRR. Cotidiano e Contextualização no Ensino de Química 84 Vol. 35, N² , p. 84-91, maio 2013. Disponível em: http://qnesc.sbq.org.br/. Acesso em: 02/06/2015.

6. POTIGUARA, AP. O que é pesquisa em educação? 2a ed. São Paulo: Paulus 2005.

7. FAZENDA, Ivani Catarina Arantes. Integração e Interdisciplinaridade no ensino brasileiro: Efetividade ou ideologia 6 ${ }^{a}$ edição: de 2011 C E EDIÇÕES LOYOLA, São Paulo, Brasil, 1979.

8. CHARLOT, Bernard. Da relação com o saber: Elementos para uma teoria. Porto Alegre: Artmed, 2000.

9. NACARATO, OM. O professor que ensina matemática: desafios e possibilidades no atual contexto. Espaço Pedagógico. v. 20, n. 1, Passo Fundo, p. 11-32, 2013

10. D’AMBROSIO, Beatriz S. Como ensinar matemática hoje? Temas e Debates. SBEM. Ano II. N2. Brasilia. 1989. p. 15-19.

11. LOPES, JR, Victer, EF; Souza, CA. O uso da história da trigonometria no ensino. Revista de Educação, Ciências e Matemática v.4 n.1 jan/abr 2014

12. LOPES. CE. A Educação Matemática no Ensino Médio Sessão Trabalho Encomendado - Anped34 2011, UNICSUL/Disponível em http:// www.ufrrj.br Acesso em 02/06/201

13. BRASIL. Ministério da Educação. Secretaria de Educação Média e Tecnológica. Parâmetros curriculares nacionais: Ensino Médio - bases legais. Brasília: MEC/ SEMTEC: Brasília, 1999a.

14. TUFANO, W. Contextualização. In: Dicionário em Construção: interdisciplinaridade. São Paulo: Cortez, 2001.

15. SANTOMÉ, JT. Globalização e interdisciplinaridade: o currículo integrado. Trad. Cláudia Schilling. Porto Alegre: Artes Médicas, 1998.

16. SKOVSMOSE O. Educação Matemática Critica: A questão da democracia. Campinas SP: Papirus 2001. 